\title{
Dietary flaxseed administered post thoracic radiation treatment improves survival and mitigates radiation-induced pneumonopathy in mice
}

Melpo Christofidou-Solomidou ${ }^{1 *}$, Sonia Tyagi ${ }^{1}$, Kay-See Tan ${ }^{2}$, Sarah Hagan ${ }^{3}$, Ralph Pietrofesa ${ }^{1}$, Floyd Dukes ${ }^{1}$, Evguenia Arguiri ${ }^{1}$, Daniel F Heitjan², Charalambos C Solomides ${ }^{4}$ and Keith A Cengel ${ }^{3}$

\begin{abstract}
Background: Flaxseed (FS) is a dietary supplement known for its antioxidant and anti-inflammatory properties. Radiation exposure of lung tissues occurs either when given therapeutically to treat intrathoracic malignancies or incidentally, such as in the case of exposure from inhaled radioisotopes released after the detonation of a radiological dispersion devise (RDD). Such exposure is associated with pulmonary inflammation, oxidative tissue damage and irreversible lung fibrosis. We previously reported that dietary FS prevents pneumonopathy in a rodent model of thoracic X-ray radiation therapy (XRT). However, flaxseed's therapeutic usefulness in mitigating radiation effects post-exposure has never been evaluated.

Methods: We evaluated the effects of a 10\%FS or isocaloric control diet given to mice (C57/BL6) in 2 separate experiments ( $n=15-25$ mice/group) on 0, 2, 4, 6 weeks post a single dose 13.5 Gy thoracic XRT and compared it to an established radiation-protective diet given preventively, starting at 3 weeks prior to XRT. Lungs were evaluated four months post-XRT for blood oxygenation levels, inflammation and fibrosis.

Results: Irradiated mice fed a 0\%FS diet had a 4-month survival rate of $40 \%$ as compared to $70-88 \%$ survival in irradiated FS-fed mouse groups. Additionally, all irradiated FS-fed mice had decreased fibrosis compared to those fed 0\%FS. Lung OH-Proline content ranged from $96.5 \pm 7.1$ to $110.2 \pm 7.7 \mu \mathrm{g} / \mathrm{ml}$ (Mean \pm SEM) in all irradiated FSfed mouse groups, as compared to $138 \pm 10.8 \mu \mathrm{g} / \mathrm{ml}$ for mice on $0 \% \mathrm{FS}$. Concomitantly, bronchoalveolar lavage (BAL) protein and weight loss associated with radiation cachexia was significantly decreased in all FS-fed groups. Inflammatory cell influx to lungs also decreased significantly except when FS diet was delayed by 4 and 6 weeks post XRT. All FS-fed mice (irradiated or not), maintained a higher blood oxygenation level as compared to mice on 0\%FS. Similarly, multiplex cytokine analysis in the BAL fluid revealed a significant decrease of specific inflammatory cytokines in FS-fed mice.
\end{abstract}

Conclusions: Dietary FS given post-XRT mitigates radiation effects by decreasing pulmonary fibrosis, inflammation, cytokine secretion and lung damage while enhancing mouse survival. Dietary supplementation of FS may be a useful adjuvant treatment mitigating adverse effects of radiation in individuals exposed to inhaled radioisotopes or incidental radiation.

Keywords: Flaxseed, radiation pneumonopathy, mitigation, lung fibrosis, antioxidant, flaxseed lignans, SDG, lung injury, ROS, inflammation, bronchoalveolar lavage, survival, cytokines, mouse model

\footnotetext{
* Correspondence: melpo@mail.med.upenn.edu

'Department of Medicine, Pulmonary Allergy and Critical Care Division,

University of Pennsylvania Medical Center, Philadelphia, PA 19104, USA

Full list of author information is available at the end of the article
} 


\section{Background}

Ionizing radiation produces deleterious effects in living organisms. Rapid technological advancement has increased human exposure to ionizing radiations. People are exposed to ionizing radiation during diagnostic and therapeutic radiographic procedures, as well as in their daily activities at the work place [1]. Humans are also exposed to ionizing radiation during air and space travel, background radiation from nuclear accidents and through the use of electronic devices. Additionally, global developments of the past decade have established terrorism as a novel and highly concerning means by which large numbers of people could be exposed to potentially lethal amounts of radiation [2].

There are at least two potential ways that a terroristic attack could expose a population to radiation injury. If terrorists gained possession of a nuclear warhead, detonation could release large amounts of radiation (in a single "blast") that could induce radiation sickness, bone marrow damage and potential lung injury. More likely, however, the weapon of radiological terrorism would be a "dirty bomb", or a radiological dispersion device (RDD). In a RDD, conventional explosives would spread radioactive materials in the form of powder or pellets [2-4] which can spread far away from the immediate explosion and pose a high health risk if inhaled. Exposure to whole-body irradiation induces the well defined acute radiation syndrome (ARS), with symptoms from damage to hematopoietic, gastrointestinal and central nervous system [5]. However, in detonation of a RDD, the lung becomes the critical target organ for radiation injury.

Radiation pneumonopathy has been well characterized as a significant clinical toxicity from thoracic radiation $[6,7]$. Patients receiving large doses of radiation to the lung show two types of adverse clinical scenarios [8]. An acute type of radiation pneumonopathy can occur as early as two weeks after irradiation whereby a "pneumonitic" or exudative reaction occurs. In the second type of radiation-induced lung injury, occurring within several months after exposure, the lung tissue enters the "late fibrotic" phase, in which the number of inflammatory cells (particularly neutrophils) decrease and a marked thickening of alveolar walls due to collagen deposition can be noted histopathologically. Radiation pneumonopathy has been modeled in animals; the C57/ BL6 mice are especially susceptible to this fibrotic reaction [9-11].

Several agents, ranging from cytokines to receptor blockers, have been tested for their efficacy in ameliorating radiation effects $[10,12-14]$. Unfortunately most agents, even those proven to be effective as radioprotectors (i.e., tested prior to a radiation exposure), are not yet available for human use. Additionally, these agents were intended as treatments for injuries resulting from the therapeutic use of radiation which is a very different scenario than radiation injuries resulting from nuclear accidents or radiological terrorism. Specifically, in most accident or terrorism scenarios, a) treatment would not be able to be initiated until after the irradiation, therefore, eliminating agents that work only when given before irradiation; b) the radiation would be received in a short overall time and there might be agents that are effective with multi-week radiation treatments that are less effective for a single large dose of radiation and c) a potential mitigator would need to be administered to a large population of healthy individuals exposed to an undetermined dose of radiation, making it highly desirable to find a agent that is non-toxic and safe for multiple administrations lasting throughout the long exposure and recovery phase.

High toxicity and unwanted side effects associated with chemical radioprotectors (thiols, antioxidant enzymes, etc) $[15,16]$, has shifted the focus to the evaluation of the radioprotective potential of plants and herbs as well as antioxidant agents [17]. Our group has identified flaxseed and its bioactive lignan component as potent protectors against radiation-induced lung toxicity when given prior to radiation exposure [11]. Specifically, dietary flaxseed decreased radiation-induced oxidative lung tissue damage, decreased lung inflammation and prevented lung fibrosis. This study was performed to determine whether dietary flaxseed can also be effective as a mitigator of radiation toxicity, i.e., when administered after radiation exposure to the lung.

\section{Methods}

\section{Animals}

Our studies used female C57/BL6 mice, a strain well characterized in the field of pulmonary radioprotection $[18,19]$. Mice were obtained from Charles River (Wilmington, MA) and irradiated at 6-8 weeks of age under animal protocols approved by the Institutional Animal Care and Use Committee (IACUC) of the University of Pennsylvania. For this study we used $n=15$ for each of the non-irradiated control groups $(0 \% \mathrm{FS}$ and $10 \% \mathrm{FS})$ and $\mathrm{n}=25$ for each of the irradiated mouse cohorts. The data shown here represent combined data from two separate studies.

\section{Diets and dietary treatments}

Semi-purified AIN-93G diet was used as the base diet which was supplemented with $10 \%(\mathrm{w} / \mathrm{w})$ FS as described in our previous publications [11,20]. Control and experimental diets were isocaloric and identical in Physsiological fuel value. Whole ground yellow FS (Lot\# 1012338) was kindly provided by Dr. James Hammond (North Dakota State University, Fargo, ND). Diets were 
started as described in Figure 1. Importantly, mice were maintained on the respective diets for the entire duration of the experiment until termination at 4 months post-radiation exposure.

\section{Radiation procedure}

Mice were anesthetized and irradiated as previously described [10]. Briefly, using an immobilization chamber that allows bilateral exposure of the lung of up to 8 mice simultaneously while lead shielding $(3 \mathrm{~mm})$ the head, abdomen and extremities, 13.5 Gy was delivered to mid-plane using a $250 \mathrm{kVp}$ orthovoltage machine (Philips RT 250) at a dose/rate of $1.7 \mathrm{~Gy} / \mathrm{min}$ and a source to skin distance of $33 \mathrm{~cm}$, through a $0.2 \mathrm{~mm}$ copper filter and a tube current of $13 \mathrm{~mA}$. For quality assurance, thermoluminescent dosimeters were placed over selected mice to verify correct dose administration.

Analytical evaluation of lignan content in murine plasma Circulating plasma levels of the flaxseed lignans ED and EL at time of sacrifice (4 months post-XRT) were determined by liquid chromatogra Phys tandem mass spectrometry (LC/MS/MS) as described earlier [21,22] using commercially available standards in $95 \%$ purity (Chromadex, Inc., Santa Ana, CA). Plasma flaxseed lignan levels were evaluated in 3 randomly selected mice per group (irradiated mice; diet initiated at $-3,0,+2,+4,+6$ weeks of radiation exposure).

\section{Bronchoalveolar lavage fluid analysis}

Mice were sacrificed using an overdose of ketamine (100 $\mathrm{mg} / \mathrm{ml})$ and xylazine $(20 \mathrm{mg} / \mathrm{ml})$ at 4 months post-irradiation. Bronchoalveolar lavage (BAL) was then performed through a 20-gauge angiocatheter (BD Pharmingen, San Diego, CA), with the intra-tracheal instillation of $1 \mathrm{ml}$ phosphate-buffered saline (PBS) containing an anti-protease cocktail (Sigma) and $5 \mathrm{mM}$ EDTA given in $0.5 \mathrm{ml}$ increments. An aliquot was immediately separated to measure total leukocyte cell

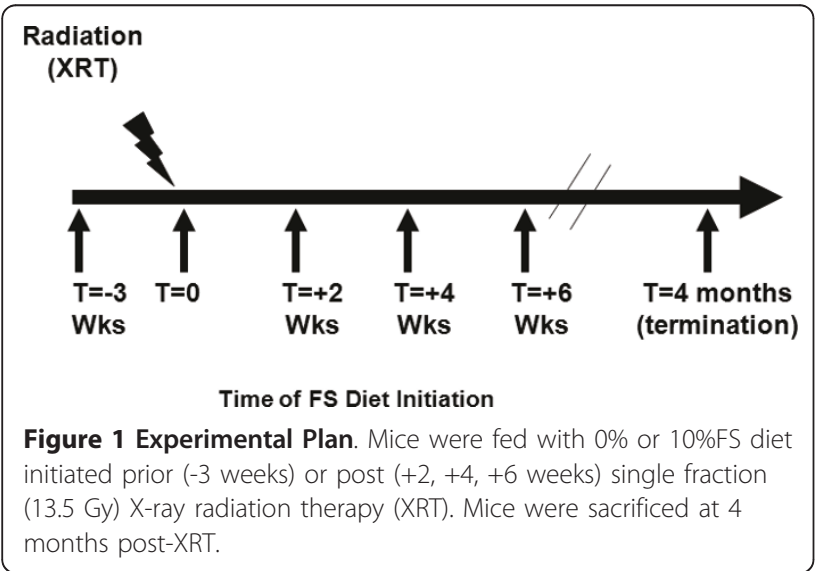

counts (cells/ml BAL fluid) using a Coulter Cell and Particle Counter (Beckman Coulter, Miami, FL). The remaining lavage fluid was centrifuged at 1,200 rpm for $10 \mathrm{~min}$ and the cell-free supernatant was frozen at $-80^{\circ}$ $\mathrm{C}$ for cytokine and protein analysis.

The amount of total protein in the BAL fluid was assayed using the BCA Protein Assay Kit (Pierce, Rockford, IL) as per manufacturer's instructions. Absorbance was read at $560 \mathrm{~nm}$ (MRX Microplate Reader, Dynatech Laboratories, Chantilly, VA) and protein levels in $\mathrm{mg} / \mathrm{ml}$ of BAL fluid were calculated.

\section{Multiplexed cytokine analysis}

The cytokine concentrations in the BAL fluid were assayed using Invitrogen's Mouse Cytokine 20-Plex Panel (LMC0006). This panel permits simultaneous quantification of multiple cytokines in solution by capturing them onto antibody coated spectrally distinct fluorescent microspheres and measuring fluorescence intensity using the BioPlex 200 (Bio-Rad Laboratories, Hercules, CA) system. The kit quantified 20 mouse cytokines and chemokines: FGF-basic, Granulocyte Macrophage Colony-Stimulating Factor (GM-CSF), interferon- $\gamma$ (IFN- $\gamma$ ), Interleukin (IL)$1 \alpha$, IL-1 $\beta$, IL-2, IL-4, IL-5, IL-6, IL-10, IL-12 (p40/p70), IL-13, IL-17, IP-10, keratinocyte-derived chemokine (KC), Monocyte Chemoattractant Protein-1 (MCP-1), Macrophage Inflammatory Protein-1 $\alpha$ (MIP-1 $\alpha$ ), MIG, Tumor Necrosis Factor $-\alpha$ (TNF- $\alpha$ ) and vascular endothelial growth factor (VEGF). The assay was performed according to the manufacturer's protocol. All the samples were run in duplicate. The detection limit of this kit is in $\mathrm{pg} / \mathrm{ml}$ for all the included cytokines.

\section{Tissue harvesting and evaluation of oxidative lung injury} Radiation experiments were terminated after 16 weeks, corresponding to a time point when radiation-induced fibrosis is readily detectable in our model $[10,21,22]$ using both biochemical assays and histopathological evaluation. For histological studies, the lungs were instilled prior to removal from the animal with $0.75 \mathrm{ml}$ of buffered formalin through a 20-gauge angiocatheter placed in the trachea, immersed in buffered formalin overnight and processed for conventional paraffin histology. Sections were stained with hematoxylin and eosin and examined by light microscopy. Malondialdehyde (MDA), an indicator of oxidative stress [23] was measured in homogenized lung tissues using a commercially available kit (OXIS International, Portland, OR) according to manufacturer's protocol. The results were expressed as $\mu \mathrm{mol} \mathrm{MDA/g}$ of lung protein.

\section{Oxygen saturation measurements}

We used a mouse-adapted Pulse-oximeter (Starr Life Sciences, Oakmont, PA) as a non-invasive clinical 
readout of lung function post XRT in mice [24]. Mice were shaved around the neck area to remove black hair that interfered with detection and a pulse-oximeter clip was placed on the neck, over the carotid arteries. Mice were allowed to walk freely in a small chamber covered by a light blocking fabric supplied by the manufacturer. In some instances, mice were pre-adapted to the feeling of the neck sensor collar by adding a mock collar on them for a day prior to evaluation. Three minute readings were taken from each mouse, measurements containing error codes were removed and the average of the remaining readings was calculated (usually those ranged from 1000-3000). On a limited number of mice, arterial blood gas analysis of carotid blood was performed using an i-STAT blood gas analyzer (Abbott Laboratories, East Windsor, NJ) using G3+ cartridges and results compared to those from pulse oximetry.

Quantitative and semi-quantitative assessment of fibrosis Collagen content of mouse lung was evaluated quantitatively by determining hydroxy-proline ( $\mathrm{OH}$-Proline) content using acid hydrolysis [10] according to Woessner et al. [25]. The data is expressed as $\mu \mathrm{g}$ hydroxyproline/ whole lung. Semi-quantitative evaluation of fibrosis was done histologically by determining a radiation Fibrotic Index (FI) as described previously [22].

\section{Statistical analysis}

Results are expressed as mean \pm SEM of two independent experiments. Statistical differences among groups were determined using one-way analysis of variance (ANOVA). When statistically significant differences were found $(p<0.05)$ individual comparisons were made using the Bonferoni/Dunn test (Statview 4.0). We used the Cox proportional-hazard model with a timevarying predictor to evaluate the effect of FS administration on animal survival (Proc Phreg; SAS Version 9.2; SAS Institute, Cary, NC).

\section{Results}

\section{Detection of lignan content in murine plasma}

Analytical methods (LC/MS/MS) were used to detect flaxseed metabolites in the circulation to confirm that mice fed on the flaxseed-supplemented diet were reaching Physsiologically relevant levels, comparable to those in all our previous studies [11,20,22]. Mice were maintained on control $(0 \% \mathrm{FS})$ or treatment $(10 \% \mathrm{FS})$ diets given ad libitum for either three weeks prior to XRT or started on same day of XRT or 2,4,6 weeks post XRT and continued for 4 months (see scheme on Figure 1). Plasma evaluation for lignan level detection was done at 16 weeks post XRT.

Indeed (Figure 2), although variable, both ED and EL were detectable in all FS-fed mouse groups 4 months post-irradiation while no ED or EL was detectable in the control-diet fed mice. Levels of ED and EL ranged from 14-405 $\mathrm{ng} / \mathrm{ml}$ and $103-325 \mathrm{ng} / \mathrm{ml}$ of plasma, respectively. These values fall within the reported range for our studies in other models of acute and chronic lung injury $[11,20,22]$.

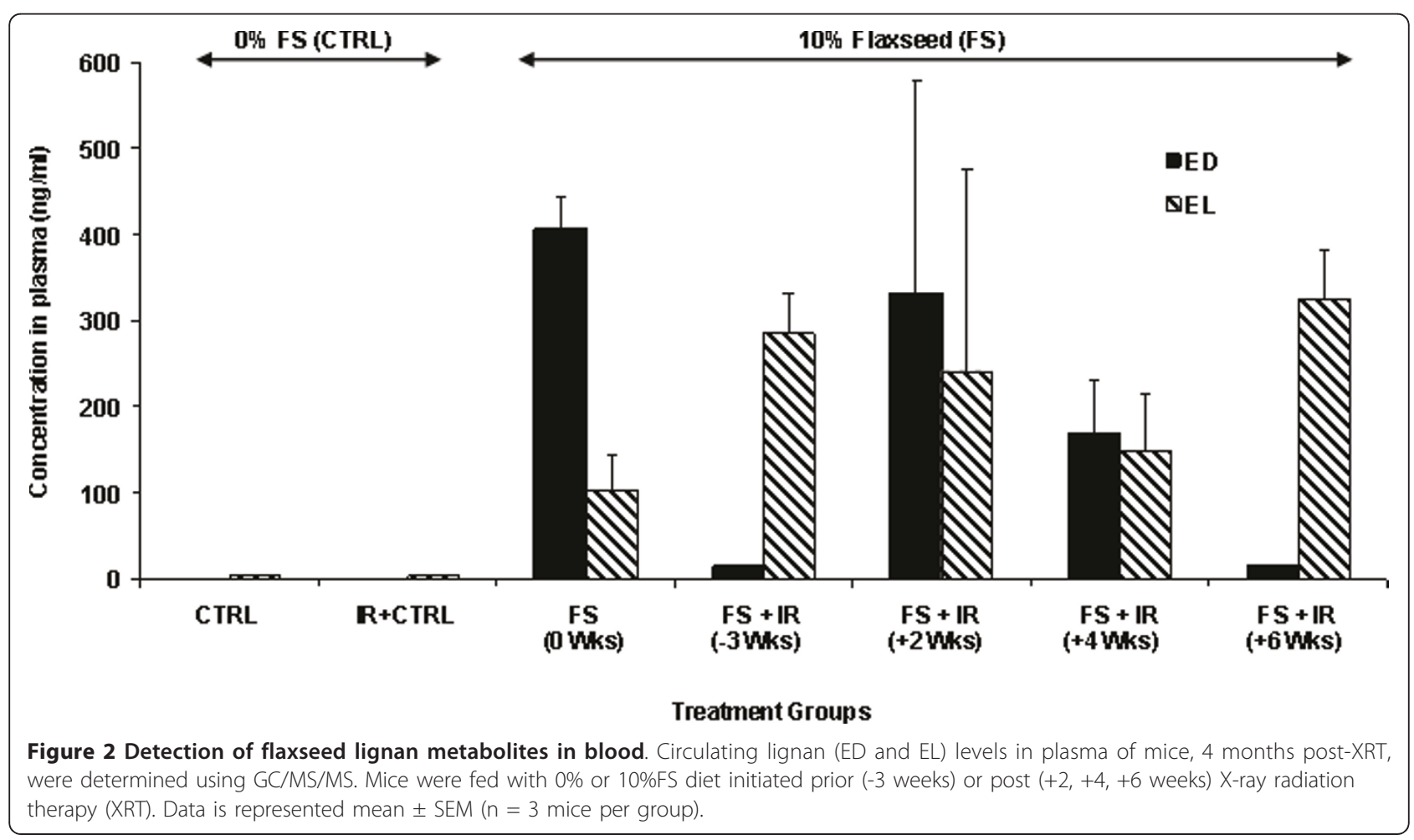




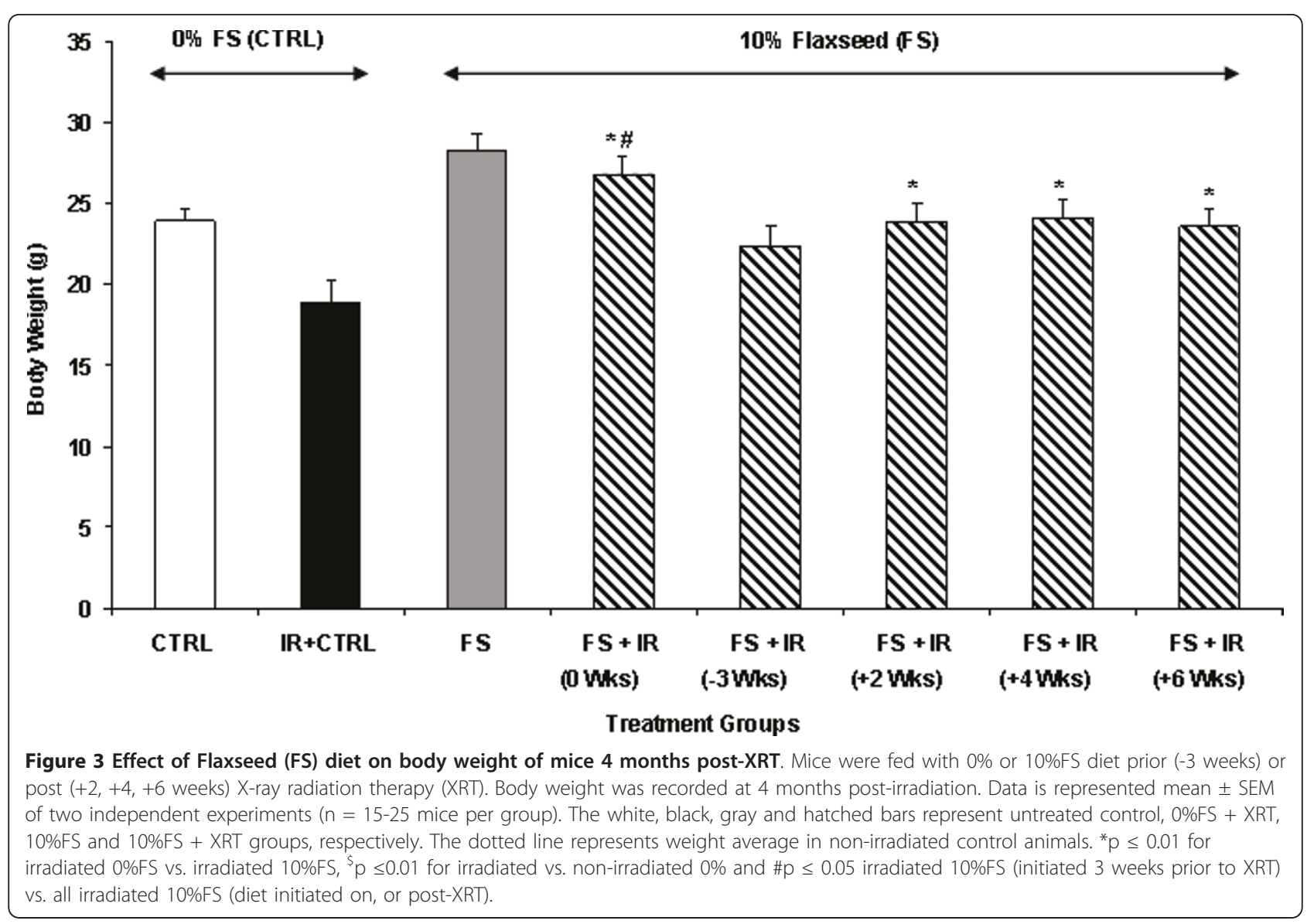

Dietary flaxseed given post-XRT ameliorates radiationinduced cachexia and boosts survival

Radiation-induced pneumonopathy is associated with cachexia measured by loss in body weight. We therefore evaluated the effect of post-irradiation administration of $10 \% \mathrm{FS}$ diet on XRT-induced loss in body weight (Figure 3 ) and survival (Figure 4) of mice. Although designed to be isocaloric, the $10 \% \mathrm{FS}$ diet given to non-irradiated mice led to a significant $(\mathrm{p}<0.007)$ difference in body weight $(28.2 \pm 1.07 \mathrm{~g})$ as compared to non-irradiated mice on the $0 \% \mathrm{FS}$, control diet $(23.8 \pm 0.83 \mathrm{~g})$. A fair comparison, therefore, of dietary treatments $(0 \%$ vs. $10 \%)$ would be to compare each diet regimen with the non-irradiated counterparts. As anticipated, XRT decreased the body weight $(18.9 \pm 1.37 \mathrm{~g})$ of animals on the $0 \%$ control diet significantly ( $\mathrm{p} \leq 0.01$ ) as compared with their non-irradiated counterparts. Remarkably, the $10 \%$ FS supplementation, whether given 3 weeks prior to irradiation or several weeks thereafter, significantly prevented XRT-induced weight loss. The only exception was the condition where diet was initiated on the day of irradiation. In this group, the body weight was not significantly different than the $0 \%$ FS fed irradiated group.
XRT (13.5 Gy, 0\%FS)-induced radiation sickness and early mortality was observed in all groups, albeit to variable degree, within the first 2-3 weeks of exposure (Figure $4 \mathrm{~A})$. We have observed this effect previously, and attributed this early death to poor oral intake possibly from esophagitis. Later deaths, occurring in 8-16 weeks are attributed to radiation pneumonopathy. However, by 4 months post XRT, only $40 \%$ of animals survived in the irradiated group ( $0 \% \mathrm{FS})$, as compared to the nonirradiated counterparts (Figure 4B). These values fall within the previously observed survival rate [22], given that the selected dose of 13.5 Gy reflects the LD50 as shown in our previous studies. Interestingly, $10 \% \mathrm{FS}$ diet led to a significant $(p<0.05)$ increase in the survival of animals in all groups when compared with irradiated group (XRT, 0\%FS). When 10\%FS diet was started preventively, i.e., 3 weeks prior to XRT, survival was enhanced significantly $(80 \%$; $<<0.05)$ in comparison to irradiated group, a finding in agreement with previous observations. Remarkably, flaxseed diet, when given therapeutically, i.e., initiated post-XRT, enhanced the survival of all irradiated animal groups. When $10 \%$ FS diet was given to animals up to 6 weeks post-irradiation, animal survival increased significantly $(\mathrm{p}<0.05)$. 
Dietary FS given post-XRT improves pulmonary hemodynamics and mitigates pulmonary inflammation and oxidative lung injury

Thoracic radiation is associated with pneumonopathy characterized by inflammatory cell influx and pulmonary edema. We have previously shown that preventive use of dietary FS decreased radiation-induced lung damage and inflammation [22]. To test whether FS also mitigates these effects when administered at variable times post radiation challenge, we delayed the dietary administration $(0,2,4,6$ weeks) and evaluated BAL at 4 months post-XRT. We confirmed BAL findings with a histopathological evaluation of lungs in mice belonging in the same groups of mice, which, however, were not lavaged, so that histological evaluation would not be compromised.

We observed a significantly reduced inflammatory cell influx (Figure 5A) in the BAL fluid from lungs in all irradiated mouse groups fed with $10 \% \mathrm{FS}$ diet as compared with those on control diet, regardless of the time the diet was initiated (pre- or post-XRT). Alveolar protein level is a marker for increased lung permeability and lung injury. Alveolar protein exudate was increased 37 -fold $(3.78 \pm 1.19 \mathrm{mg} / \mathrm{ml})$ in mice 4 months postXRT (Figure 5B) in comparison to untreated controls $(0.1 \pm 0.013 \mathrm{mg} / \mathrm{ml})$. These findings correlated with the histopathological evaluation (Figure 6). In summary, FS diet significantly $(\mathrm{p}<0.05)$ decreased lung injury and edema by decreasing the XRT-induced alveolar protein levels irrespective of therapeutic or preventive administration.

Radiation pneumonopathy is also associated with compromised pulmonary function resulting in poor oxygenation levels as modeled in rodent models [26]. Pulse oximetry is a non-invasive way of determining arterial blood oxygenation levels (Figure 5C). XRT notably decreased the percentage of arterial $\mathrm{O}_{2}$ levels $(61.4 \% \pm$ $10.77 \%$ ) in mice fed with $0 \%$ control diet in comparison to untreated control animals $(78.5 \% \pm 5.33 \%)$. Mice Fed with $10 \% \mathrm{FS}$ diet had an increase percentage of arterial $\mathrm{O}_{2}$ levels compared to mice fed 0\% diet following XRT. FS diet enhanced blood oxygenation, thus improving pulmonary hemodynamics in irradiated mice irrespective of whether it was given therapeutically or preventively.

\section{Dietary FS mitigates oxidative lung changes when given post-thoracic XRT}

Lipid peroxidation plays a major role in mediating oxidative-damage in tissues. Thoracic radiation-induced oxidative degradation of unsaturated fatty acids can be followed by determining the amount of a product, malondialdehyde (MDA), of lipid peroxidation in lung tissues [21,22]. A significant two-fold increase in MDA levels was recorded in irradiated animals fed with control diet as compared to unchallenged controls (Figure 7). In contrast, mice fed with a $10 \% \mathrm{FS}$ diet (whether given preventively or therapeutically) maintained a significantly ( $\mathrm{p} \leq 0.005$ ) lower MDA level at 4 months post-XRT in all the treatment groups (diet initiated -3 or $0,2,4,6$ weeks post XRT) as compared to irradiated mice fed with $0 \% \mathrm{FS}$ diet. Importantly, no statistical difference was found among any of the irradiated FS-fed groups (Figure 7, hatched bars) and the non-irradiated FS group (Figure 7, grey bar).

\section{Dietary FS mitigates fibrotic changes in lung tissue when given post-thoracic XRT}

Dietary flaxseed prevents radiation-induced pulmonary fibrosis in mice when given preventively [22]. However, its effects when given therapeutically, i.e., post the radiation challenge, are unknown. To test this, we evaluated the total OH-Proline content of murine lungs 4 months post-XRT (Figure 8A). This is a quantitative measure of collagen deposition and fibrosis in lungs, which is expressed as $\mu \mathrm{g} \mathrm{OH}$-proline/lung. XRT led to a significant ( $\mathrm{p} \leq 0.0001)$, near 2-fold increase of OH-Proline in mice $(0 \% \mathrm{FS})$ in comparison to unchallenged controls. FS diet rendered a noteworthy decline in OH-Proline levels in all radiation-challenged mice. Mice fed with $10 \% \mathrm{FS}$ diet prior or post-XRT had significantly ( $\mathrm{p} \leq 0.005)$ deceased levels of $\mathrm{OH}$-Proline content in comparison to those fed with 0\%FS following XRT (Figure 8A).

To further evaluate the degree of XRT-induced fibrosis and correlate biochemical findings with tissue histology, lungs were also examined histolopathologically using Trichrome staining (Figure 9) and Fibrotic Index (FI) score, a measure of the extent of lung fibrosis and inflammation, was determined for each lung (Figure 8B). Lungs of irradiated mice fed with $0 \% \mathrm{FS}$ diet showed severe fibrosis (Figure 9B, blue color) as compared to non-irradiated mice $(0 \% \mathrm{FS})$. The extent of fibrosis was notably reduced in all animal groups fed with $10 \% \mathrm{FS}$ diet prior or post-XRT when compared to irradiated $0 \%$ FS fed mice.

\section{Alterations of pro-inflammatory and pro-fibrotic cytokine profile in the BAL fluid of FS-fed mice 4 months post-XRT} Thoracic radiation-induced cytokines, chemokines and cell adhesion molecules are implicated in the pathogenesis of pulmonary inflammation, both subacute and chronic, as well as in the development of lung fibrosis [27]. To determine the beneficial effects of FS given several weeks post radiation challenge, we evaluated inflammatory cytokine levels in BAL fluid in mice sacrificed 4 months post XRT (Table 1). This time coincides with radiation pneumonitis and the onset of detectable lung fibrosis. Using multiplex cytokine analysis, we analyzed the effect of FS on a panel of 20 cytokines. While half 


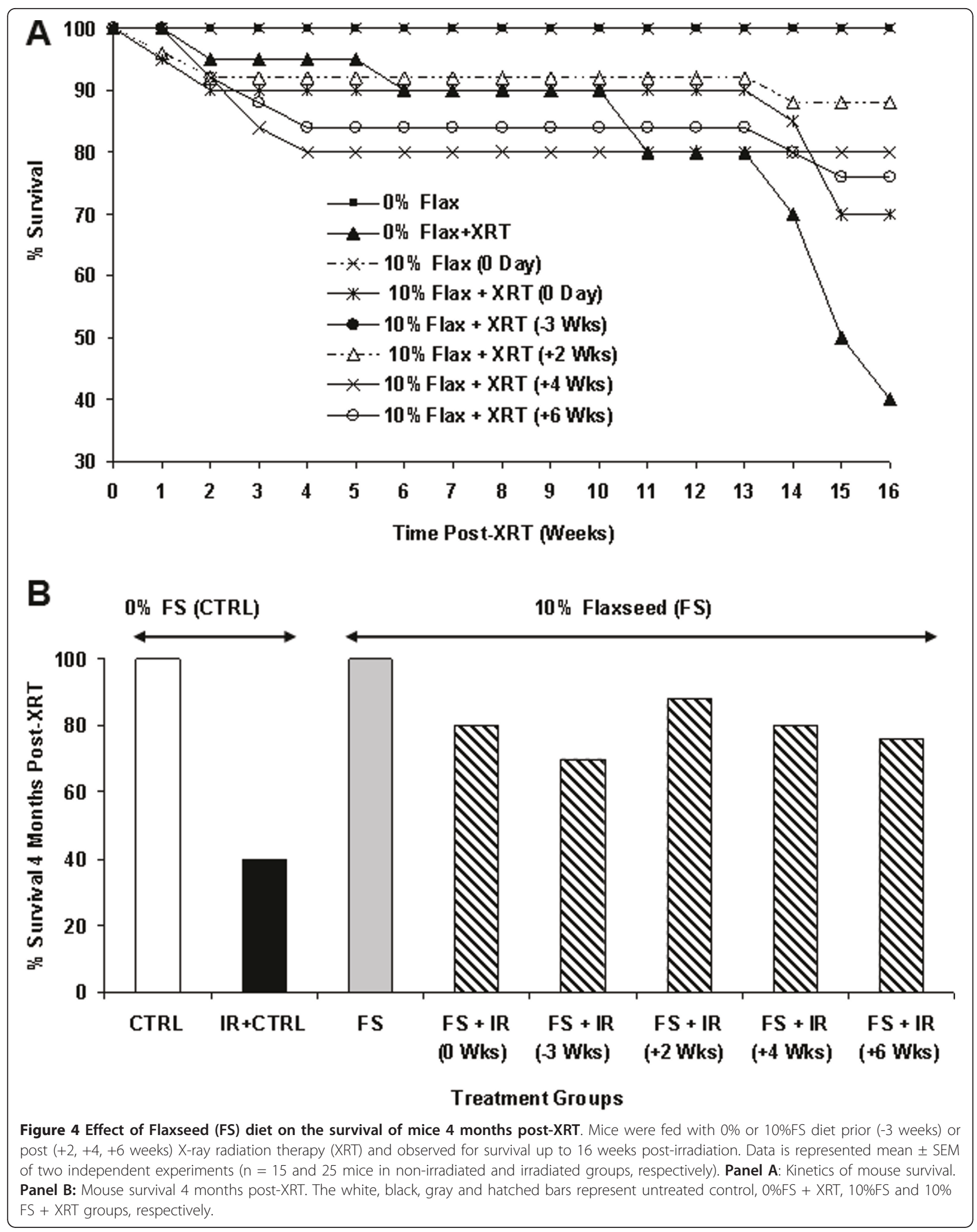



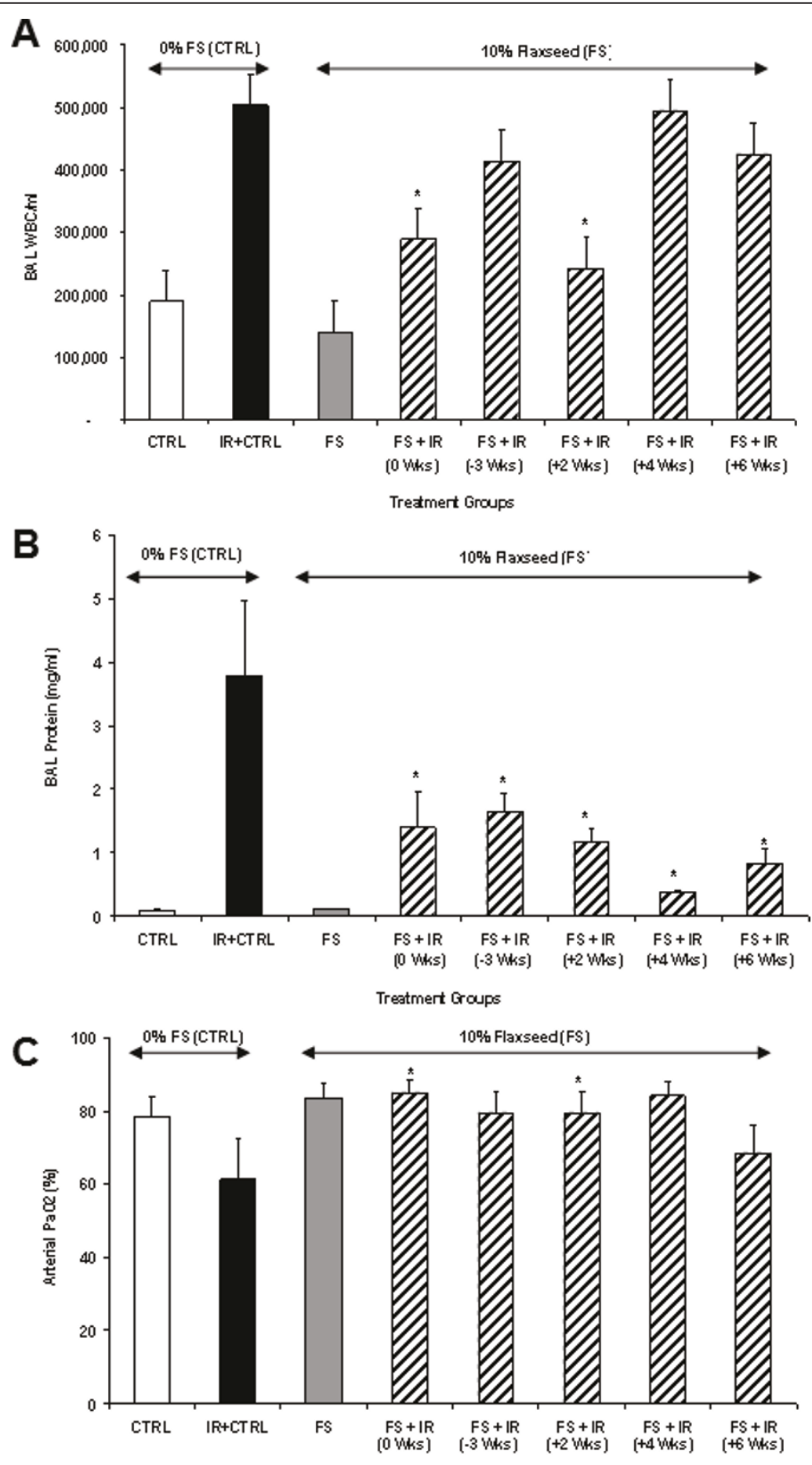

Treatmert Groups

Figure 5 Evaluation of Lung Injury, Inflammation and Blood Oxygenation Levels in mice $\mathbf{4}$ months post-XRT. Mice were fed with $0 \%$ or $10 \%$ FS diet at designated times $(-3,0,+2,+4,+6$ weeks) of X-ray radiation therapy (XRT). Data is represented mean \pm SEM of two independent experiments ( $n=15-25$ mice per group). Panel A: Total WBC counts in bronchoalveolar lavage (BAL) of irradiated (13.5 Gy, XRT) mice after 4 months. ${ }^{*} p \leq 0.05$ for irradiated 0\%FS vs. irradiated 10\%FS Panel B: Total proteins in BAL of mice after 4 months. ${ }^{*} p \leq 0.01$ for irradiated 0\%FS vs. irradiated 10\%FS Panel C: Arterial $\mathrm{O}_{2}$ levels were measured using pulse oximetry in irradiated (13.5 Gy, XRT) mice after 4 months. The white, black, gray and hatched bars represent untreated control, 0\%FS + XRT, 10\%FS and 10\%FS + XRT groups, respectively. ${ }^{*} \mathrm{p} \leq 0.05$ for irradiated $0 \%$ FS vs. irradiated $10 \%$ FS. 

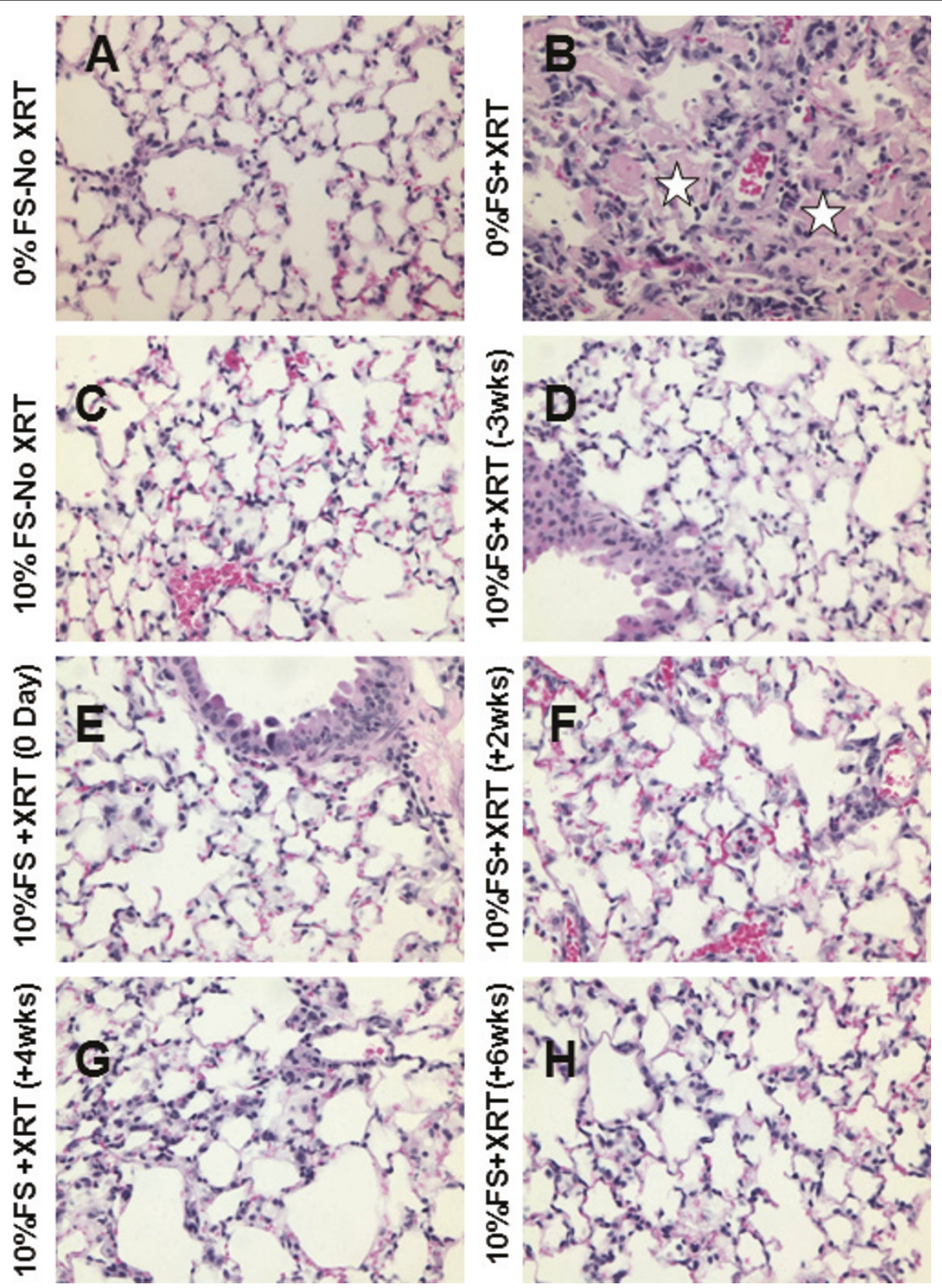

Figure 6 Histological evaluation of lung Hematoxylin and Eosin (H\&E)-stained sections post-XRT (4 months). Mice were fed with $0 \%$ or $10 \%$ FS diet prior ( -3 weeks) or post $(+2,+4,+6$ weeks) X-ray radiation treatment (XRT). Lungs were harvested 4 months post single fraction XRT and processed for histology. Asterisks designate proteinaceous exudate in alveolar spaces.

the cytokines (basic FGF, GM-CSF, IFN- $\gamma$, IL-1 $\alpha$, IL-5, MCP-1, TNF- $\alpha$ ) were at levels below the detection limit of the assay, 10 cytokines (IL1 $\beta$, IL-2, IL-4, IL-6, IL-12, IL-17, IP-10, KC, MIG, MIP- $\alpha$ and VEGF) were measurable in the BAL fluid of all mouse groups.

A significant decrease in the levels of IL-1 $\beta$, IL-2, IL-4, MIG, or MIP-1 $\alpha$ was detected in all of the irradiated FS diet fed groups as compared to irradiated mice on control diet. However, levels of IL-6, IL-12, IL-17 and
VEGF were significantly lower in irradiated FS-fed mice as compared to irradiated mice on control diet. Notably, even delaying FS diet by as long as 6 weeks post-radiation challenge resulted in a several-fold decrease of the above-mentioned cytokines.

\section{Discussion}

We demonstrate here for the first time the role of FS in boosting survival and mitigating the acute and chronic 


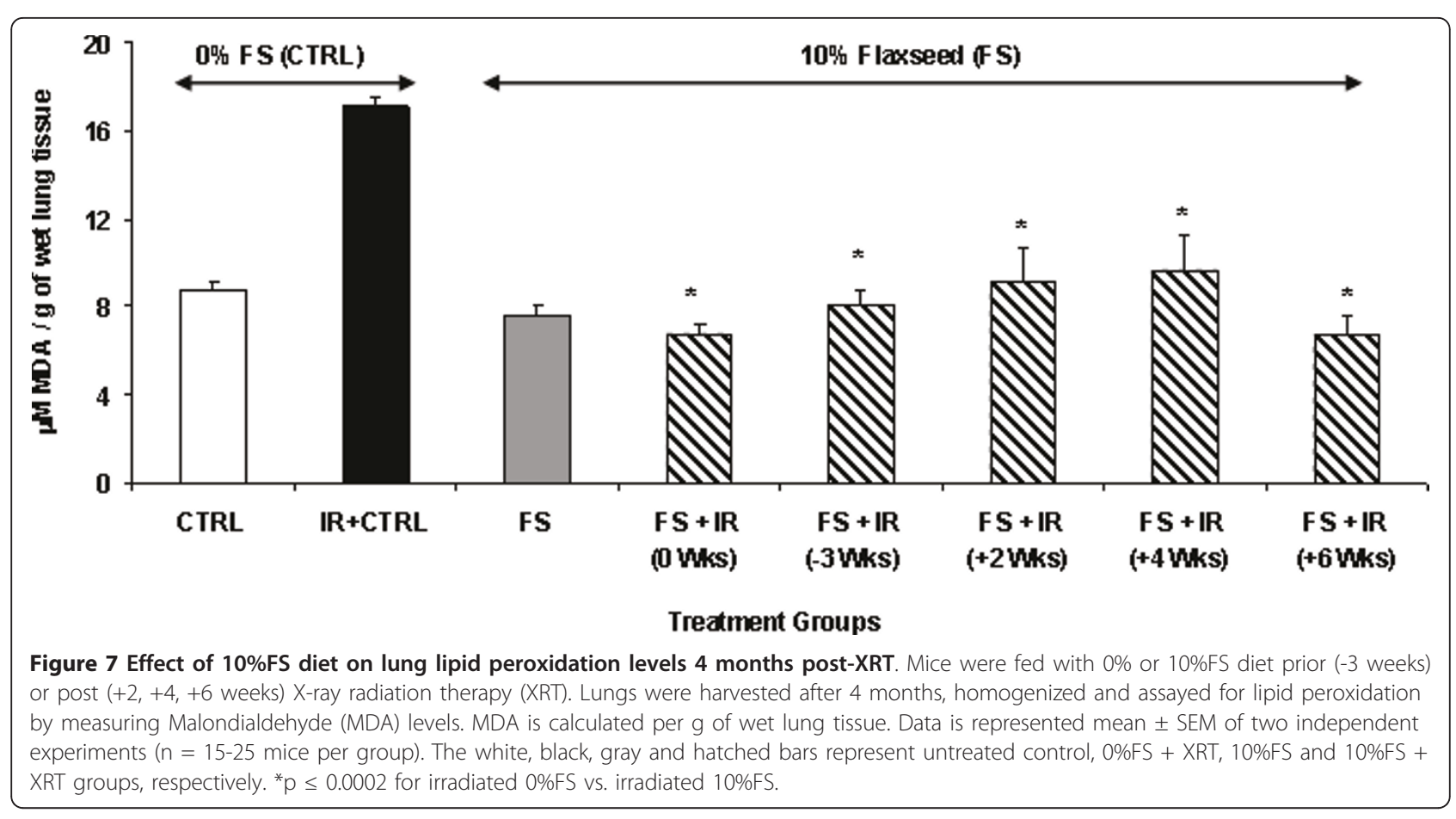

damage induced by $\mathrm{X}$-ray radiation exposure of lung tissues when administered days and even weeks after radiation exposure. Results from our study show that FS significantly ameliorates the XRT-induced damage by improving survival and body weight of mice fed with FS not only when diet was given prior to XRT but also when diet was started 2, 4 and 6 weeks after XRT. We also found that FS diet mitigated the deleterious effects of XRT by: a) improving pulmonary hemodynamics and blood oxygenation levels, b) decreasing lung injury by lowering BAL protein levels, c) reducing pulmonary fibrosis by decreasing collagen content of lung tissues, d) reducing lung inflammation by decreasing WBC influx into the airways and by e) oxidative modification of mouse lungs as evidenced by levels of lipid peroxidation. BAL cytokine analysis, moreover, pointed to an alteration of the chronic inflammatory profile of irradiated lungs favoring a mitigated radiation effect as a result of the FS diet.

Some reports suggest using lung lavage to remove radionuclides inhaled after a dirty bomb detonation as a possible countermeasure $[28,29]$. However, this remains an impractical countermeasure since multiple lavages may be required for efficient removal of radionuclide burden while the procedure itself is associated with known risks of an invasive procedure that requires anesthesia. Alternatively, a plethora of compounds both chemical/natural are being evaluated with the intent of mitigating radiation damage [17]. To date Amifostine is the only FDA approved cytoprotective radiation mitigator. However, the use of Amifostine has been limited by its significant systemic toxicity [17]. Further, most of the compounds that offered a positive radioprotection on cells have not shown efficacy in pre-clinical animal studies.

An ideal radiation mitigator should be safe, effective, have a long shelf life and an easy route of administration. Flaxseed, due to its high content of lignans and omega-3 fatty acids, is a dietary supplement that has numerous medicinal, anti-inflammatory and antioxidant properties. FS and its bioactive components have been extensively studied for their anti-inflammatory $[11,20]$, anticarcinogenic [30,31] and anti-atherogenic effects [32] in several organ systems. Importantly, prolonged FS administration has not been associated with any significant toxicity [33]. Therefore, we hypothesized that flaxseed may be an effective, safe and cost-effective mitigator of the radiation damage.

Our data showed that $10 \%$ FS diet supplementation significantly increased the survival in mice in all the irradiated groups (Figure 4) irrespective of the time of initiation of the FS diet (70-88\% survival) as compared to the survival of mice fed with $0 \%$ FS diet (40\% survival). It is evident from our results that FS diet protects mice from XRT-induced mortality whether given therapeutically or preventively. Improvement of survival using antioxidants such as N-acetyl-Cysteine (NAC) or mitochondrion-targeted small molecule radiation damage mitigators has been shown in mouse models of abdominal irradiation [34] or total body irradiation [35] 


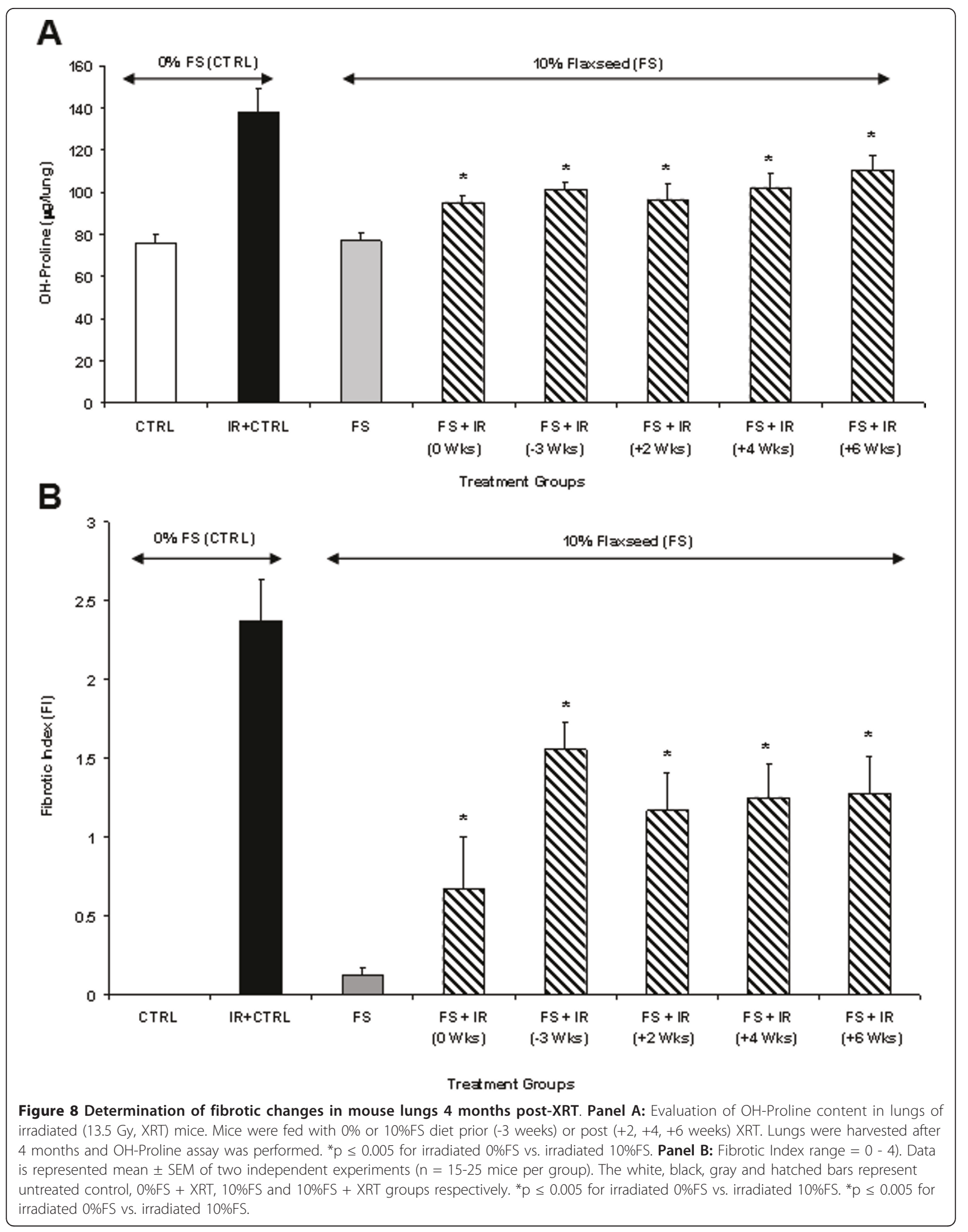



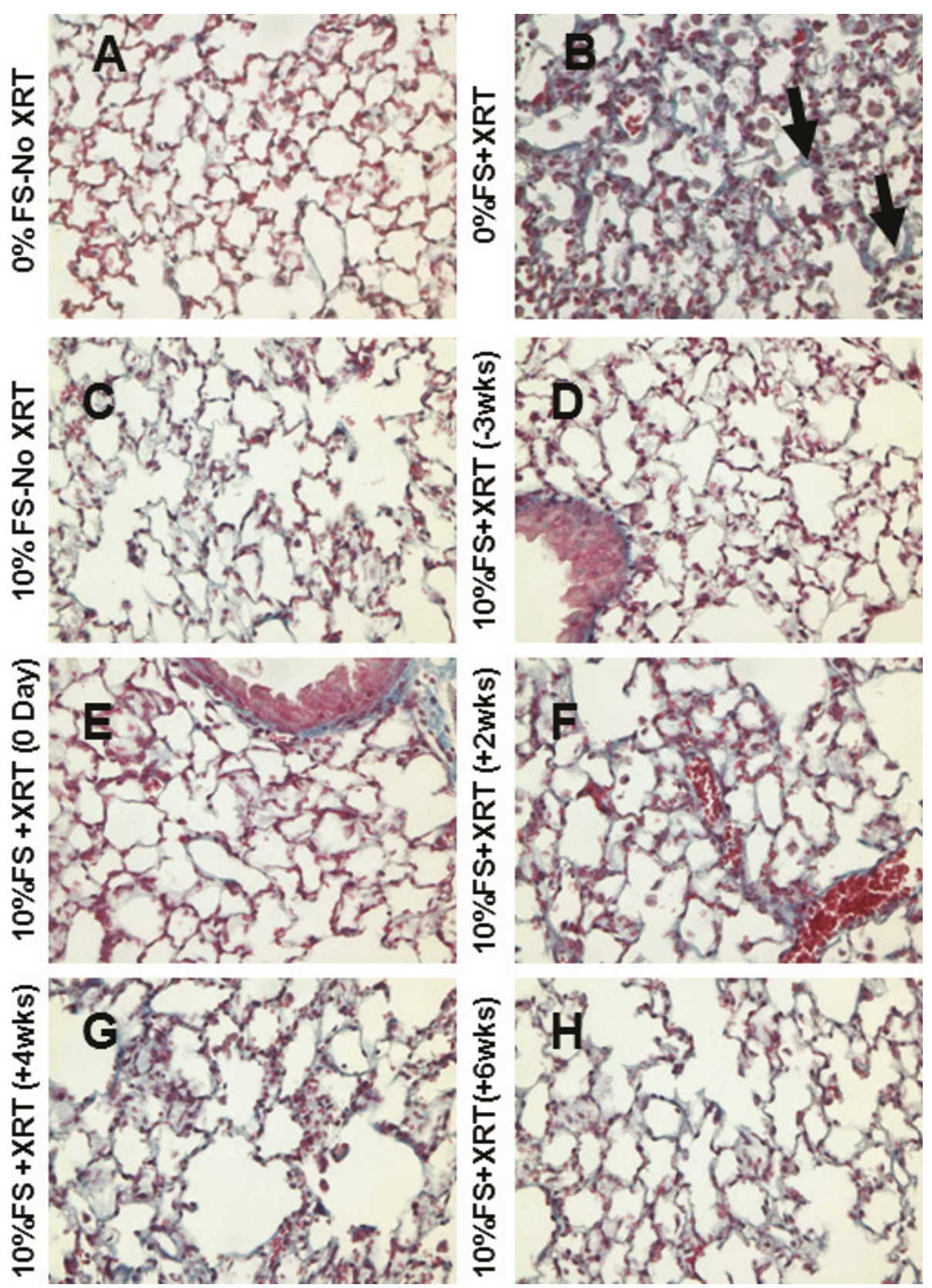

Figure 9 Histological evaluation of lung Trichrome-stained sections post-XRT (4 months). Mice were fed with 0\% or 10\%FS diet prior (-3 weeks) or post $(+2,+4,+6$ weeks) XRT. Lungs were harvested 4 months post single fraction XRT and processed for histology. Arrows designate collagen deposition in lung (blue color).

respectively. To our knowledge our study is the first to report that a mitigator of radiation damage improves survival of animals in an experimental model of thoracic radiation damage. Results revealed radiation-induced increment in lipid peroxidation in lungs (Figure 7). Lipid peroxidation (LP) results from a cascade of events induced by radiation in biological membranes. FS diet led to a significant drop off in the LP levels in all the FS-fed experimental mouse groups. Some reports show that other plant extracts also decrease radiation-induced LP [36]. Recent work by Gauter-Fleckenstein et al. [37] showed mitigation of radiation-induced oxidative lung tissue changes by an superoxide dismutase (SOD) mimetic, although beneficial effects of the mitigator were limited. Oxidative stress in lungs was only then mitigated when the SOD mimetic was given up to 24 hours post radiation and not when given days (3 days) or weeks (8 weeks) post irradiation. In our work the 
Table 1 Evaluation of cytokine levels in BAL of mice 4 months post-XRT

\begin{tabular}{|c|c|c|c|c|c|c|c|c|c|}
\hline $\begin{array}{c}\text { Treatment } \\
\text { Groups }\end{array}$ & $-1 \beta$ & -4 & -6 & $\begin{array}{c}\text { IL-12 } \\
(p 40 / p 70)\end{array}$ & -17 & KC & MIG & AIP-1 $\alpha$ & VEGF \\
\hline ב & $7 \pm 8.3$ & $3.6 \pm 6.3$ & $.0 \pm 5.9$ & $19.2 \pm 3.1$ & $6 \pm 0.2$ & $658.6 \pm 39.3$ & $5.3 \pm 2.5$ & $25.4 \pm 7.8$ & $26.6 \pm 4.6$ \\
\hline $0 \% \mathrm{FS}+\mathrm{XF}$ & $1 \pm 2.7$ & $4 \pm 1.0$ & $66.0 \pm 42.5$ & $88.1 \pm 18.2$ & $4 \pm 0.1$ & $173.0 \pm 47.0$ & $11.4 \pm 4.2$ & 3.7 & $43.9 \pm 4.5$ \\
\hline $10 \% \mathrm{FS}$ & $14.4 \pm 5.1$ & 20. & $16.6 \pm 2.0$ & & & $730.7 \pm$ & 4.4 & & \\
\hline 10\%FS + XRT (0 Day) & $12.4 \pm 0.8$ & $18.2 \pm 0.3$ & $20.4 \pm 1.1^{\$}$ & $51.1 \pm 13.3^{5}$ & $0.6 \pm 0.1$ & $521.0 \pm 165.0^{*}$ & $20.9 \pm 4.9$ & 13.3 & $21.4 \pm 3.8^{\#}$ \\
\hline $10 \% \mathrm{FS}+\mathrm{XRT}(-3 \mathrm{wks})$ & $14.7 \pm 1.5$ & $17.9 \pm 0.6$ & $28.0 \pm 6.4$ & $54.2 \pm 13.6^{*}$ & $0.9 \pm 0.3^{*}$ & $396.0 \pm 49.3$ & $14.8 \pm 2.8$ & 1.6 & $16.9 \pm 3.4^{\#}$ \\
\hline $10 \% \mathrm{FS}+\mathrm{XRT}(+2 \mathrm{wks})$ & $13.1 \pm 2.9$ & 15. & $16.6 \pm 1$ & $43.2 \pm 7.9^{*}$ & & 380 & 0 & 14 & \\
\hline $10 \% \mathrm{FS}+\mathrm{XRT}(+4 \mathrm{wks})$ & $7.4 \pm 1.0$ & $16.6 \pm 0.6$ & $13.0 \pm 1.8^{*}$ & $16.2 \pm 1.2^{\# \S}$ & $0.1 \pm 0.0^{\S \S}$ & $444.0 \pm 66.8$ & $8.8 \pm 1.6$ & $10.0 \pm 1.2$ & $6.8 \pm 2.2^{\#}$ \\
\hline $10 \% \mathrm{FS}+\mathrm{XRT}$ (+6 wks) & $7.7 \pm 1.2$ & $16.5 \pm 0.9$ & $15.3 \pm 1.7^{\$}$ & $26.8 \pm 7.1^{\#}$ & $0.2 \pm 0.0^{\S \S}$ & $264.7 \pm 150.7$ & $9.0 \pm 4.8$ & $10.0 \pm 2.1$ & $11.7 \pm 1.8^{\#}$ \\
\hline
\end{tabular}

Mice were fed with $0 \%$ or $10 \%$ FS diet prior ( -3 weeks) or post $(+2,+4,+6$ weeks) X-ray radiation therapy (XRT) and sacrificed after 4 months. Lungs were lavaged and cytokine levels in BAL were measured. Data is represented mean \pm SEM of two independent experiments ( $n=15$ and 25 mice in non-irradiated and irradiated groups, respectively). Values are mean \pm SEM of two independent experiments. $\mathrm{n}=15$ and 25 in non irradiated and irradiated groups respectively. ${ }^{\$} \underline{p} \leq 0.05,{ }^{*} \underline{p} \leq 0.01,{ }^{*} \underline{p} \leq 0.0005$, for $0 \%$ FS irradiated vs. $10 \%$ FS irradiated groups.

${ }_{\mathrm{p}} \mathrm{p} \leq 0.05,{ }^{\S \S} \mathrm{p} \leq 0.01$ for $10 \% \mathrm{FS}$ given preventively to XRT Vs $10 \%$ FS started therapeutically post-XRT.

drop in lipid peroxidation of lung tissues was significant even when the FS diet was initiated 4 and 6 weeks post radiation challenge. Further, our lab is currently exploring dietary formulations of flaxseed components, to identify the chief bioactive ingredient(s) that mitigate radiation effects.

Radiation-induced inflammation is an important side effect that contributes to normal tissue injury [7]. Our results indicated that XRT-induced lung inflammation and impaired blood oxygenation (decreased $\mathrm{P}_{\mathrm{a}} \mathrm{O} 2$ ) were improved with FS diet when initiated prior to or, importantly, days and weeks after XRT. Vujaskovic and coworkers [38] have shown that severe hypoxia develops months post an initial radiation exposure of lung tissues. Such hypoxia contributes significantly to the development of a cascade of events leading to lung injury. Improved blood oxygenation of all FS-fed mouse groups (Figure 5C) may lead to decreased levels of tissue hypoxia and may thus, explain mitigation of adverse radiation effects even when diets are initiated post challenge. In fact, recent work by the same group [37] using an SOD mimetic to mitigate tissue hypoxia, showed that this would be possible even when given weeks post-irradiation, something which further corroborates with our findings with the FS diet. Decrease of radiation-induced lung inflammation by a mitigator has never been shown. This is the first report that antioxidant agents, such as the FS diets, mitigate pulmonary inflammation when given weeks post initial challenge.

A major feature of radiation pneumonitis is a considerable increase in the alveolar protein exudates, an indicator of increased vascular permeability and direct lung injury [38]. Radiation causes damage to resident lung cells which in turn release inflammatory mediators (cytokines) and recruit inflammatory cells to the site [39]. BAL protein level is the most direct and reliable measure of lung injury, translating in actual tissue damage while activation markers of lung tissue inflammatory cell content such as the macrophage ED-1 marker, is a measure rather of inflammation and not injury [37]. Our results show a significant mitigation of lung injury in all the experimental FS diet fed groups, regardless of the time of FS diet initiation. This may be attributed to decreased inflammatory cell influx and membrane oxidation in FS-supplemented mice. This is the first report that an agent is reported to mitigate Physsiological lung injury from radiation in vivo.

Radiation pneumonitis also involves irreversible fibrotic changes in lung tissues occurring in the late phase of the radiation response [40]. We have shown that wholegrain FS was protective against experimental radiation fibrosis [22]. Our current study showed for the first time that fibrotic processes can be blunted in pulmonary tissues even when the protective agent is given post-radiation damage, i.e., as a radiation mitigator. Despite notable benefits of a therapeutic usefulness of FS diet (i.e., when initiated at $0,+2,+4$ and +6 weeks post XRT), however, the fact remained that FS-mediated decline in both lung $\mathrm{OH}$-Proline levels and FI was more prominent when diet was started preventively, i.e., 3 weeks prior to XRT. This is the first time that any botanical or chemical agent is indicating mitigation of fibrotic changes effect in lungs.

Radiation exposure leads to histologically recognizable chronic injury initiated by a series of molecular responses involving a number of inflammatory cytokines, pro-fibrotic cytokines and chemokines produced by a variety of cell types, including macrophages, epithelial cells and fibroblasts $[27,39,41]$. While many studies in rodent thoracic irradiation models focus on cytokine release during the initial post-irradiation phase [41], studies such as those of Rubin et al. [39] analyzed the cytokine profile in lungs during the late, chronic phase. In the present study, we evaluated the effect of FS diet on inflammatory cytokines in the late phase of thoracic radiation-exposed mice. As expected, the cytokine levels 
of the lung tissues and fluids measured in our model reflect levels comparable to those in chronic inflammation and not in acute responses. Several cytokines associated with inflammation were significantly lower in irradiated FS-fed mice as compared to irradiated mice on control diet, while no other cytokines were significantly aggravated by the FS diet. Our studies show, for example, a sustained 3-fold increased BAL level of IL-6 in radiation-exposed mice if fed a control diet while dietary supplementation of flaxseed, given even weeks post initial insult, decreased IL-6 levels, reflecting a low inflammatory state of lung tissues.

Radiation-induced pulmonary injury consists of an early latent period followed by chronic inflammation that leads to collagen deposition and ultimately to fibrosis. Studies suggest that chronic inflammation occurs due to the release of cytokines, chemokines, growth factors and it induces the development of fibrosis. Rubin et al. [39] reported that a perpetual cascade of cytokines activated soon after radiation exposure that leads to late pulmonary fibrosis.

In the present study we also evaluated the effect of FS diet on inflammatory cytokines in radiation-exposed murine models. Macrophage inflammatory protein 1- $\alpha$ (MIP-1 $\alpha$ ) appears to be an important cytokine mediator of pulmonary inflammation and injury. Growing preclinical and clinical data suggest a potential relationship between serum MIP-1 $\alpha$ levels and the risk of lung injury following thoracic radiation.

Increased production of IL-6 is known to occur in the chronic inflammation scenario. It stops production of TNF- $\alpha$, an acute phase inflammatory cytokine, and is found in chronic disease conditions like thyroditis and type I diabetes. Our studies also show a high level of IL6 in radiation-exposed mice. Dietary supplementation of flaxseed decreased IL-6 levels, indicating a low inflammatory state. Both IL-4 and IL-17 are known to induce IL-6 production. However in our study, the increase in IL-6 in radiation exposed mice cannot be attributed to IL-17 and IL-4 as both these cytokines showed lower expression as compared to untreated controls.

IL-12 is an inducer of cell mediated inflammation. In our studies, decreased IL-4 expression in radiation exposed mice was concomitant with increase in IL-12 expression. This antagonistic nature of IL-4 and IL-12 is well reported in literature. When flaxseed was given therapeutically or preventively to irradiated mice, it led to a decrease in IL-12 expression without changing IL-4 status. Flaxseed thus seems to decrease cell mediated inflammation by decreasing IL-12 levels although it does not have any effect on IL-4.

VEGF is identified as an endothelial cell specific growth factor that contributes to angiogenesis and vascular permeability. Radiation exposure to lungs induces hypoxia [42] and hypoxia itself induces ROS generation which in turn promotes inflammation and vascular damage, activates pro-fibrotic cytokines, and promotes collagen formation. Our results corroborate these reports, as we observed increased VEGF levels in the BAL fluid of radiation-exposed mice, while in FS-fed irradiated animals low VEGF levels were observed as compared to untreated controls.

\section{Conclusion}

Because radiation damage is a multi-faceted phenomenon, any agent or compound that can modify or alter multiple aspects or mechanisms of radiation-induced inflammation and fibrosis while at the same time being both inexpensive and non-toxic is extremely exciting. It is evident from our findings that dietary FS is a potential agent in mitigating radiation damage and that the discovery of the mitigating properties of FS may prove a critical milestone in the development of non-toxic radiation mitigators.

\section{List of abbreviations}

AU: Arbitrary units; BAL F: Bronchoalveolar lavage fluid; ED: Enterolactone; EL: Enterodiol; Fl: Fibrotic Index; FS: Flaxseed; H\&E: Hematoxylin and eosin; IR: Irradiation; OH-Proline: Hydroxy-proline; LP: Lipid Peroxidation; MDA: Malondialdehyde; PMN: Polymorphonuclear leukocyte; ROS: Reactive oxygen species; SDG: Secoisolariciresinol diglucoside; SEM: Standard error means; WBC: White blood cells; XRT: X-ray Treatment.

\section{Acknowledgements and Funding}

The authors wish to thank Dr. Costas Koumenis for reviewing the manuscript and for his valuable advice in evaluating the data. Funded in part by: NIH-R01 CA133470-03 (MCS), NIH-RC1Al081251-01 (MCS), $\mathrm{NIH}$-P30 CA016520 (DH), the American Institute for Cancer Research \#AICR$03 B 024$ (MCS), the University of Pennsylvania Research Foundation (MCS) and by pilot project support from 1P30 ES013508-02 awarded to MCS (its contents are solely the responsibility of the authors and do not necessarily represent the official views of the $\mathrm{NIEHS}, \mathrm{NIH}$ ).

\section{Author details}

'Department of Medicine, Pulmonary Allergy and Critical Care Division, University of Pennsylvania Medical Center, Philadelphia, PA 19104, USA. ${ }^{2}$ Biostatistics \& Epidemiology, University of Pennsylvania Medical Center, Philadelphia, PA 19104, USA. ${ }^{3}$ Radiation Oncology, University of Pennsylvania Medical Center, Philadelphia, PA 19104, USA. ${ }^{4}$ Department of Pathology, Jefferson University Hospital, Philadelphia, PA 19140, USA.

\section{Authors' contributions}

MCS designed the study and individual experiments, analyzed data, wrote the manuscript and supervised lab personnel. ST assisted with animal experiments and manuscript preparation. $\mathrm{KT}$ performed statistical analysis of survival studies. SH performed all the irradiation procedures. RP performed animal experiments, biochemical assays and conducted data analysis. FD assisted with pulse oximetry. EA conducted animal experiments and tissue analyses. DFH performed statistical analysis of survival studies. CCS performed pathology assessment of histological specimens. KAC assisted with irradiation procedures and provided consultation on data analysis. All authors read and approved the final manuscript.

\section{Competing interests}

The authors declare that they have no competing interests.

Received: 14 February 2011 Accepted: 24 June 2011

Published: 24 June 2011 


\section{References}

1. Brenner DJ, Hall EJ: Computed tomography-an increasing source of radiation exposure. N Engl J Med 2007, 357(22):2277-2284.

2. Vogel H: Rays as weapons. Eur J Radiol 2007, 63(2):167-177.

3. Chin FK: Scenario of a dirty bomb in an urban environment and acute management of radiation poisoning and injuries. Singapore Med J 2007, 48(10):950-957.

4. Dombroski MJ, Fischbeck PS: An integrated physical dispersion and behavioral response model for risk assessment of radiological dispersion device (RDD) events. Risk Anal 2006, 26(2):501-514.

5. Moulder JE: Post-irradiation approaches to treatment of radiation injuries in the context of radiological terrorism and radiation accidents: a review. Int J Radiat Biol 2004, 80(1):3-10.

6. Machtay M: Pulmonary complications of anticancer treatment. 3 edition. Churchill Livingston; 2003.

7. Marks LB, Yu X, Vujaskovic Z, Small W Jr, Folz R, Anscher MS: Radiationinduced lung injury. Semin Radiat Oncol 2003, 13(3):333-345.

8. Keane T, Van Dyk J, Rider W: Idiopathic interstitial pneumonia following bone marrow transplantation. Int J Radiat Oncol Biol Phys 1981, 7:1365-1370.

9. Franko AJ, Sharplin J: Development of fibrosis after lung irradiation in relation to inflammation and lung function in a mouse strain prone to fibrosis. Radiat Res 1994, 140:347-355.

10. Machtay M, Scherpereel A, Santiago J, Lee J, McDonough J, Kinniry P, Arguiri E, Shuvaev W, Sun J, Cengel K, Solomides CC, ChristofidouSolomidou M: Systemic polyethylene glycol-modified (PEGylated) superoxide dismutase and catalase mixture attenuates radiation pulmonary fibrosis in the C57/bl6 mouse. Radiother Oncol 2006, 81(2):196-205

11. Lee JC, Bhora F, Sun J, Cheng G, Arguiri E, Solomides CC, Chatterjee S, Christofidou-Solomidou M: Dietary flaxseed enhances antioxidant defenses and is protective in a mouse model of lung ischemiareperfusion injury. Am J Physiol Lung Cell Mol Physiol 2008, 294(2):L255-265.

12. Travis EL, Parkins CS, Holmes SJ, Down JD, Fowler JF: WR-2721 protection of pneumonitis and fibrosis in mouse lung after single doses of x-rays. Int J Radiat Oncol Biol Phys 1984, 13:1355-1359.

13. Travis EL, Newman RA, Helbing SJ: WR 2721 modification of type II cell and endothelial cell function in mouse lung after single doses of radiation. Int J Radiat Oncol Biol Phys 1987, 13:1355-1359.

14. Epperly M, Bray J, Kraeger S, Zwacka R, Engelhardt J, Travis E, Greenberger J: Prevention of late effects of irradiation lung damage by manganese superoxide dismutase gene therapy. Gene Ther 1998, 5(2):196-208.

15. Chen $Y$, Okunieff $P$ : Radiation and third-generation chemotherapy. Hematol Oncol Clin North Am 2004, 18(1):55-80.

16. Reboul FL: Radiotherapy and chemotherapy in locally advanced nonsmall cell lung cancer: preclinical and early clinical data. Hematol Oncol Clin North Am 2004, 18(1):41-53.

17. Citrin D, Cotrim AP, Hyodo F, Baum BJ, Krishna MC, Mitchell JB: Radioprotectors and mitigators of radiation-induced normal tissue injury. Oncologist 2010, 15(4):360-371.

18. Dileto CL, Travis EL: Fibroblast radiosensitivity in vitro and lung fibrosis in vivo: comparison between a fibrosis-prone and fibrosis-resistant mouse strain. Radiat Res 1996, 146(1):61-67.

19. Sharplin J, Franko AJ: A quantitative histological study of straindependent differences in the effects of irradiation on mouse lung during the early phase. Radiat Res 1989, 119(1):1-14

20. Kinniry P, Amrani Y, Vachani A, Solomides CC, Arguiri E, Workman A, Carter J, Christofidou-Solomidou M: Dietary flaxseed supplementation ameliorates inflammation and oxidative tissue damage in experimental models of acute lung injury in mice. J Nutr 2006, 136(6):1545-1551.

21. Lee JC, Kinniry PA, Arguiri E, Serota M, Kanterakis S, Chatterjee S, Solomides CC, Javvadi P, Koumenis C, Cengel KA, ChristofidouSolomidou M: Dietary curcumin increases antioxidant defenses in lung, ameliorates radiation-induced pulmonary fibrosis, and improves survival in mice. Radiat Res 2010, 173(5):590-601.

22. Lee JC, Krochak R, Blouin A, Kanterakis S, Chatterjee S, Arguiri E, Vachani A, Solomides CC, Cengel KA, Christofidou-Solomidou M: Dietary flaxseed prevents radiation-induced oxidative lung damage, inflammation and fibrosis in a mouse model of thoracic radiation injury. Cancer Biol Ther 2009, 8(1):47-53.
23. Esterbauer H, Schaur RJ, Zollner H: Chemistry and biochemistry of 4hydroxynonenal, malonaldehyde and related aldehydes. Free Radic Biol Med 1991, 11(1):81-128.

24. Verhoeven D, Teijaro JR, Farber DL: Pulse-oximetry accurately predicts lung pathology and the immune response during influenza infection. Virology 2009, 390(2):151-156.

25. Woessner JF Jr: The determination of hydroxyproline in tissue and protein samples containing small proportions of this imino acid. Arch Biochem Biophys 1961, 93:440-447.

26. Zhang R, Ghosh SN, Zhu D, North PE, Fish BL, Morrow NV, Lowry T, Nanchal R, Jacobs ER, Moulder JE, Medhora M: Structural and functional alterations in the rat lung following whole thoracic irradiation with moderate doses: injury and recovery. Int J Radiat Biol 2008, 84(6):487-497.

27. Chiang CS, Liu WC, Jung SM, Chen FH, Wu CR, McBride WH, Lee CC, Hong $\mathrm{JH}$ : Compartmental responses after thoracic irradiation of mice: strain differences. Int J Radiat Oncol Biol Phys 2005, 62(3):862-871.

28. Morgan GW, Pharm B, Breit SN: Radiation and the lung: A reevaluation of the mechanisms mediating pulmonary injury. Int J Radiat Oncol Biol Phys 1995, 31:361-369.

29. Muggenburg BA, Boecker BB, Hahn FF, McClellan RO: Lung lavage therapy to lessen the biological effects of inhaled 144Ce in dogs. Radiat Res 1990, 124(2):147-155.

30. Dwivedi C, Natarajan K, Matthees DP: Chemopreventive effects of dietary flaxseed oil on colon tumor development. Nutr Cancer 2005, 51(1):52-58

31. Thompson LU, Rickard SE, Orcheson LJ, Seidl MM: Flaxseed and its lignan and oil components reduce mammary tumor growth at a late stage of carcinogenesis. Carcinogenesis 1996, 17(6):1373-1376.

32. Bloedon LT, Szapary PO: Flaxseed and cardiovascular risk. Nutr Rev 2004, 62(1):18-27.

33. Rodriguez-Leyva D, Dupasquier CM, McCullough R, Pierce GN: The cardiovascular effects of flaxseed and its omega-3 fatty acid, alphalinolenic acid. Can J Cardiol 2010, 26(9):489-496.

34. Jia D, Koonce NA, Griffin RJ, Jackson C, Corry PM: Prevention and mitigation of acute death of mice after abdominal irradiation by the antioxidant N-acetyl-cysteine (NAC). Radiat Res 2010, 173(5):579-589.

35. Rwigema JC, Beck B, Wang W, Doemling A, Epperly MW, Shields D, Goff JP, Franicola D, Dixon T, Frantz MC, Wipf P, Tyurina Y, Kagan VE, Wang H, Greenberger JS: Two strategies for the development of mitochondriontargeted small molecule radiation damage mitigators. Int J Radiat Oncol Biol Phys 2011, 80(3):860-868.

36. Bhatia $A L$, Jain M: Spinacia oleracea L. protects against gamma radiations: a study on glutathione and lipid peroxidation in mouse liver. Phytomedicine 2004, 11(7-8):607-615.

37. Gauter-Fleckenstein B, Fleckenstein K, Owzar K, Jiang C, Reboucas JS, Batinic-Haberle I, Vujaskovic Z: Early and late administration of MnTE-2PyP5+ in mitigation and treatment of radiation-induced lung damage. Free Radic Biol Med 2010, 48(8):1034-1043.

38. Park KJ, Oh YT, Kil WJ, Park W, Kang SH, Chun M: Bronchoalveolar lavage findings of radiation induced lung damage in rats. J Radiat Res (Tokyo) 2009, 50(3):177-182.

39. Rubin $P$, Johnston $C J$, Williams JP, McDonald S, Finkelstein JN: A perpetual cascade of cytokines postirradiation leads to pulmonary fibrosis. Int J Radiat Oncol Biol Phys 1995, 33(1):99-109.

40. Travis EL, Harley RA, Fenn JO, Klobukowski CJ, Hargrove HB: Pathologic changes in the lung following single and multi-fraction irradiation. Int $J$ Radiat Oncol Biol Phys 1977, 2(5-6):475-490.

41. Ao X, Zhao L, Davis MA, Lubman DM, Lawrence TS, Kong FM: Radiation produces differential changes in cytokine profiles in radiation lung fibrosis sensitive and resistant mice. J Hematol Oncol 2009, 2:6.

42. Vujaskovic Z, Anscher MS, Feng QF, Rabbani ZN, Amin K, Samulski TS, Dewhirst MW, Haroon ZA: Radiation-induced hypoxia may perpetuate late normal tissue injury. Int J Radiat Oncol Biol Phys 2001, 50(4):851-855.

\section{Pre-publication history}

The pre-publication history for this paper can be accessed here: http://www.biomedcentral.com/1471-2407/11/269/prepub

doi:10.1186/1471-2407-11-269

Cite this article as: Christofidou-Solomidou et al: Dietary flaxseed administered post thoracic radiation treatment improves survival and mitigates radiation-induced pneumonopathy in mice. BMC Cancer 2011 $11: 269$. 